\title{
VALORIZAÇÃO DO TRABALHO HUMANO E INCLUSÃO SOCIAL NO BRASIL: A RESPONSABILIDADE EMPRESARIAL E AS POLITICAS PÚBLICAS PARA A INCLUSÃO DAS PESSOAS COM DEFICIÊNCIA
}

\author{
Larissa Aparecida Costa ${ }^{1}$ \\ Lourival José de Oliveira
}

\begin{abstract}
RESUMO
O presente estudo tem como objetivo, através do método dedutivo, analisar o alcance da efetividade da valorização do trabalho humano por meio da inclusão das pessoas com deficiência no mercado de trabalho. Partindo da tutela constitucional da dignidade da pessoa humana, fundamento da República Federativa do Brasil e da ordem econômica, busca-se desnudar a responsabilidade das empresas na inclusão da pessoa com deficiência, legitimando mecanismos políticos e jurídicos, diante da imprescindibilidade em conceder a máxima efetividade dos direitos fundamentais dessa minoria, processo este que inclui o direito ao trabalho, enquanto condição indispensável à conquista da plena cidadania e aperfeiçoamento democrático.
\end{abstract}

Palavras-chave: Responsabilidade Empresarial; Pessoa com deficiência; Valorização do Trabalho Humano; Aperfeiçoamento Democrático; Cidadania.

\section{VALORIZATION OF HUMAN LABOR AND SOCIAL INCLUSION IN BRAZIL: BUSINESS RESPONSIBILITY AND PUBLIC POLICIES FOR THE INCLUSION OF PERSONS WITH DISABILITIES}

\begin{abstract}
The present study aims, through the deductive method, to analyze the effectiveness of the valorization of human work through the inclusion of people with disabilities in the labor market. Based on the constitutional protection of the dignity of the human person, the foundation of the Federative Republic of Brazil and the economic order, it seeks to strip the responsibility of companies in the inclusion of persons with disabilities, legitimizing political and legal mechanisms, given the indispensability in granting maximum effectiveness Of the fundamental rights of this minority, a process which includes the right to work as a prerequisite for the achievement of full citizenship and democratic perfection.
\end{abstract}

\footnotetext{
${ }^{1}$ Mestranda pela Universidade de Marília - Empreendimentos econômicos, desenvolvimento e mudança social. Professora Auxiliar da disciplina de Direito Processual Civil VII do Centro Universitário Antônio Eufrásio de Toledo. Pós-graduanda em Direito Penal e Processo Penal pelo Centro Universitário Antônio Eufrásio de Toledo. Membro da Comissão da Jovem Advocacia da 29a Subseção da OAB/SP. Estagiária docente no Centro Universitário Antônio Eufrásio de Toledo. Graduada em Direito pelo Centro Universitário Antonio Eufrásio de Toledo (2015). Tem experiência na área de Direito, com ênfase em Direito Constitucional, Direito Internacional, Direitos Humanos e Direito Penal. Membro do Grupo de estudos de Direito Internacional com foco no Sistema Interamericano de proteção aos Direitos Humanos. Bolsista no programa de mobilidade tendo cursado 5 meses de graduação na Universidade de Coimbra/Portugal (2014).

${ }^{2}$ Curso de Graduação em Direito pela Universidade Estadual de Londrina (1988), Graduação em História pela Universidade Estadual de Londrina (1989), Mestrado em Direito das Relações Sociais pela Universidade Estadual de Londrina (1994) e doutorado em Direito das Relações Sociais pela Pontifícia Universidade Católica de São Paulo (1999).
} 
Keywords: Inclusion. Corporate Responsibility. Disabled person. Valuing Human Work. Democratic Improvement. Citizenship.

\section{INTRODUÇÃO}

Frente ao novo modelo de desenvolvimento econômico gerado pela globalização, criando maior integração e o aumento da competitividade no mercado, o presente estudo, por meio do método dedutivo e levantamento bibliográfico, busca discutir a possibilidade de efetivação da valorização do trabalho humano, por meio da inclusão das pessoas com deficiência no mercado de trabalho, desnudando os desafios a serem superados a fim de alcançar dignidade e cidadania.

Para tanto, considerando a dignidade da pessoa humana, que abrange a proteção de um nível mínimo de subsistência e autonomia, a valorização da pessoa humana, enquanto centro das normas jurídicas, se efetiva em grande medida no direito ao trabalho, uma vez que por meio deste o individuo integra-se ao meio social e deflagra sentimentos de pertença e identidade com a comunidade.

Cuidou-se ainda de apontar de forma breve, a concepção de pessoa com deficiência no Brasil e a aplicação teórico-jurídica a partir das recentes alterações trazidas pela Convenção sobre os Direitos das Pessoas com Deficiência da Organização das Nações Unidas, a fim de deslindar as implicações, desafios e barreiras que obstam a plena cidadania dessa minoria constantemente alijadas do mercado de trabalho.

Afastado das idealizações e conjecturas em torno dos padrões de normalidade pré-estabelecidos; apartado do ideal do homem médio; a condição humana e o ideal de fraterno que nos identificado como iguais, apesar das diferenças, nos direciona para o único caminho possível para o progresso coletivo, que passa forçosamente pela consolidação de uma sociedade plural e inclusiva.

Considerando o paradigma da inclusão, que deve orientar o Poder Público e toda a sociedade, cumpre destacar as importantes alterações trazidas pela Convenção sobre os Direitos das Pessoas com Deficiência e, consequentemente, pelo Estatuto da Pessoa com Deficiência, que entrou em vigor no Brasil no começo de 2016, que tem o escopo de apresentar a deficiência sob a perspectiva da pluralidade e emancipação, deixando assim, de figurar como impeditivo a cidadania e ao trabalho digno. 
A promoção do desenvolvimento humano, na sociedade contemporânea, sob a ótica do mercado de trabalho, se estabelece por meio da tutela aos direitos consubstanciados na legislação interna e internacional, que deve ser preconizada pelo Estado, pelas empresas, e pelos sindicatos.

\section{O TRABALHO HUMANO E A INCLUSÃO NA ERA DOS DIREITOS}

A Constituição Federal de 1988 estabelece a dignidade da pessoa humana como fundamento da República Federativa do Brasil, e orienta a vasta legislação infraconstitucional, descrevendo uma ampla gama de direitos e garantias aos cidadãos e as minorias, dentre as quais destacamos as pessoas com deficiência.

Entretanto, em que pese à positivação, diuturnamente acompanhamos graves violações aos direitos humanos das pessoas com deficiência, consubstanciadas, sobretudo, pelas formas de exclusão e negação de direitos, muitas delas constatadas no mercado de trabalho.

É principalmente no mercado de trabalho que os cidadãos promovem interações sociais capazes de potencializar suas capacidades como indivíduo e integrarse efetivamente à sociedade. Sendo assim, uma analise mais detida é capaz de apresentar as barreiras que afastam as pessoas com deficiência do exercício da plena cidadania.

Nesse sentido, frente ao novo desenho de desenvolvimento gerado pela globalização no Estado Democrático de Direito, a possibilidade de efetivação da valorização do trabalho humano pode ser alcançado por meio da inclusão das pessoas com deficiência no mercado de trabalho.

Cumpre destacar que o princípio da dignidade da pessoa humana figura como um dos fundamentos do sistema constitucional, atuando como suporte axiológico ao arcabouço legislativo, como assevera Rocha (1999, p. 23/47):

\footnotetext{
A constitucionalização do princípio da dignidade da pessoa humana modifica, em sua raiz, toda a construção jurídica: ele impregna toda a elaboração do Direito, porque ele é o elemento fundante da ordem constitucionalizada e posta na base do sistema. Logo, a dignidade da pessoa humana é princípio havido como superprincípio constitucional, aquele no qual se fundam todas as escolhas políticas estratificadas no modelo de Direito plasmado na formulação textual da Constituição.
} 
Sendo assim, a primazia atribuída pelo texto constitucional a dignidade da pessoa humana, entre outras implicações, reclama uma efetiva proteção do trabalho humano, que deve ser concebido em condições de igualdade.

Devemos considerar que o princípio da igualdade, coloca-se como pilar para a consolidação de uma sociedade inclusiva, pautada na isonomia legislativa, para efetivar a inclusão e o respeito às diferenças no mercado de trabalho.

Sobre o tema, Luiz Alberto David Araújo (1996, p. 45.) afirma que:

A igualdade formal deve ser quebrada diante de situações que, logicamente, autorizam tal ruptura. Assim, é razoável entender-se que a pessoa portadora de deficiência tem, pela sua própria condição, direito à quebra da igualdade, em situações das quais participe com as pessoas sem deficiência.

Devemos considerar que propiciar relações de igualdade entre os cidadãos, é condição elementar ao processo democrático, não só do ponto de vista da ordem econômica, mas, sobretudo, considerando o âmbito sociocultural de nossa sociedade, que ainda padece de diferenciações entre os cidadãos.

As "eleições" diuturnas de camadas sociais que terão pleno gozo de sua cidadania, afeta em especial as minorias, dentre as quais destacamos as pessoas com deficiência.

Diante do panorama atual, Bobbio (1992, p. 24) faz uma ressalva importante para o estudo da ciência do direito, pois a questão que persiste não versa sobre a positivação de direitos fundamentais, mas sim sobre sua efetivação na Era dos Direitos.

Nesse sentido, o "direito a ter direitos" exposto por Hannah Arendt, ganha novos contornos diante das relações humanas na pós-modernidade, e mais ainda, frente aos influxos da globalização no mercado de trabalho. Na contemporaneidade, o status civitatis, não se limite a mera positivação de direitos e garantias, por vezes fadadas ao limbo (2001, p.5), mas sim, a partir dos elementos que diferenciam os indivíduos, oportunizar condições de atuar efetivamente no contexto social e na consolidação de uma sociedade plural e democrática.

Segundo, José Afonso da Silva (2000, p. 129), a democracia não pode ser considerada como um valor-fim, antes de tudo ela é o "meio e instrumento de realização de valores essenciais de convivência humana, que se traduzem basicamente nos direitos humanos". 
Dessa forma, vislumbrar a pessoa humana, como sujeito de direitos, livres e iguais para atuar junto à comunidade, passa necessariamente por considerar as potencialidades humanas, por meio das quais o homem se identifica com o corpo social. Sobre o tema, Eduardo Cambi (2010, p. 392) destaca trecho de voto de um julgado da Corte Interamericana de Direitos Humanos:

A vida humana não é apenas subsistência. Ela é uma existência que se dignifica em situações onde um indivíduo pode atingir seu máximo potencial. A plena realização dessa ideia é o objetivo de uma visão enriquecida dos direitos fundamentais, mas também de uma democracia realmente efetiva.

No plano Constitucional, a declaração de que a República Federativa do Brasil abriga como um de seus fundamentos os "valores sociais do trabalho", ao lado da soberania, da cidadania, da dignidade da pessoa humana e do pluralismo político; declarando que a ordem econômica tem como objetivo assegurar a todos a existência digna, finalidade alcançada por meio dos ditames da justiça social e respeito aos princípios e garantias norteadoras do sistema normativo, dentre os quais destacamos a busca do pleno emprego (Artigo 170, VIII).

A Constituição Federal abriga em seu Artigo $6^{\circ}$, entre os direitos sociais fundamentais, o direito ao trabalho, sendo que deste decorrem ampla gama de direitos e garantias aplicáveis à relação de emprego.

Com vistas ao desenvolvimento econômico, o mercado de trabalho na atualidade, pode colocar-se como mecanismo de exclusão, que nega oportunidades a determinados grupos, a fim de atender os interesses do capital econômico. Entretanto, não podemos olvidar que o trabalho digno garante aos indivíduos acesso social e participação política, capaz de gerar plena integração a comunidade.

Nesse panorama Sassaki (1997, p. 95) enfatiza que o trabalho contribui para o desenvolvimento pleno do indivíduo, contribuindo para o desenvolvimento de sua autoestima e integração social.

Considerando a proteção aos valores sociais do trabalho, expressos na Constituição Federal, vislumbra-se a importância do trabalho humano na sociedade contemporânea. Nesse sentido, o Ministro Eros Grau (2005, p.199) assevera:

Valorização do trabalho humano e reconhecimento do valor social do trabalho consubstanciam cláusulas principiológicas que, ao par de afirmarem a compatibilização - conciliação e composição - a que acima referi, portam em si evidentes potencialidades transformadoras. Em sua interação com os demais princípios contemplados no texto constitucional, expressam prevalência dos valores do trabalho na conformação da ordem econômica - 
prevalência que José Afonso da Silva reporta como prioridade sobre os demais valores da economia de mercado.

Do ponto de vista cultural, o trabalho permite que o indivíduo participe do 'mundo', incorporando valores coletivos e contribuindo para o progresso social e econômico. Para Oliveira $(2011$, p. 24.) “através do trabalho, expressa-se a vida e produz-se o homem". Sendo assim, por meio das relações de trabalho o indivíduo promove mudanças na ordem social e a si mesmo.

Em relação à sistematização normativa, Oliveira (2011, p. 23) destaca que a valorização do trabalho humano figura como um dos fundamentos da República Federativa do Brasil (art. $1^{\circ}$, IV) e que a ordem social tem como base o primado do trabalho e, como objetivo, o bem estar e a justiça social (art. 193), a fim de propiciar a plena dignidade do indivíduo.

Nada obstante os recentes movimentos de inclusão social, com vistas a superar as barreiras culturais e sociais, ainda persiste a injustificável crença na inaptidão das pessoas com deficiência para atender às exigências do mercado de trabalho, relegando a estes sujeitos de direitos posições de menor importância ou, em grande medida o mercado informal; negando a possibilidade de serem atores de sua própria história e participarem de forma efetiva dos diversos contextos sociais.

Dessa forma, o indivíduo que é despojado do mercado de trabalho vivencia dificuldades na integração cultural, na participação social e ainda na distribuição de riquezas, panorama inconciliável com a justiça social e a isonomia disposta pela Magna Carta. Em relação a violação sistemática dos direitos humanos no tocante a inclusão, Alves (2010, p. 57) observa a própria história e formação do país:

O fenômeno da inclusão social é complexo e particularmente enraizado em
países de modernidade tardia. Não se tratando apenas de exclusão
econômico-financeira, mas de exclusão sócio-política, cultural e jurídica.
Inclusive com a negação da proteção devida aos direitos humanos, que se
vêem violados de forma diuturna e sistemática quando o sujeito de direitos é
grupo minoritário. É possível, em um exercício teórico e meticuloso e
complicado, explicar a exclusão social a partir da natureza da própria
sociedade brasileira, ou pelo menos a partir de sua estrutura constituinte.

Assim sendo, tanto para a adequada tutela jurisdicional, quanto para a efetivação de políticas públicas de inclusão, cumpre analisar o conceito de pessoa com deficiência, estabelecido pela Convenção da ONU (CDPcD/2008), em consonância com 
a conjuntura histórica e cultural do país, considerando a necessidade de valorização do trabalho humano.

Para tanto, importante destacar que o conceito de pessoa com deficiência encontra-se em constante aprimoramento, como decorrência direta do princípio da dignidade da pessoa humana, a fim de contemplar as novas realidades sociais. Assim à luz de um controle de convencionalidade é possível observar que a definição de pessoa com deficiência abrange diversas possibilidades, e, portanto, o rol é amplo e em constante redefinição, no intuito de alcançar seu propósito maior de promover e assegurar os direitos das pessoas com deficiência.

A Convenção da ONU inova na acepção acerca da deficiência, atribuindo destaque a autonomia e a emancipação, que passam a ser tidos como um direito fundamental, posto que integram a dimensão da dignidade da pessoa humana.

O Decreto Legislativo no 186/2008 inseriu a Convenção sobre os Direitos das Pessoas com Deficiência, da ONU, na ordem jurídica nacional, com status material e análogo-formal de emenda constitucional, consoante previsões do art. $5^{\circ}$, $\S 2^{\circ}$ e $3^{\circ}$, da Constituição. Segundo a legislação vigente as pessoas com deficiência são aquelas que têm impedimentos de longo prazo, sejam estes de natureza física, mental, intelectual ou sensorial, os quais, em interação com diversas barreiras, podem dificultar sua participação plena na sociedade em igualdades de condições com as demais pessoas.

O Estatuto da Pessoa com Deficiência foi influenciado diretamente, inclusive com expressa referência no seu art. $1^{\circ}$, parágrafo único, pela Convenção sobre os Direitos das Pessoas com Deficiência e seu Protocolo Facultativo (Nova York/2007). A Convenção foi aprovada como emenda à Constituição, em conformidade com o art. $5^{\circ}$, $\S \S 2^{\circ}$ e $3^{\circ}$, da Constituição Federal (Decreto Legislativo $n^{\circ} 186 / 2008$ ), passando a valer no ordenamento jurídico brasileiro com o Decreto Presidencial n ${ }^{\circ} 6.949$ de 25 de agosto de 2009. Destarte, as previsões internacionais passaram a fazer parte do rol de direitos constitucionais brasileiros, levando à necessidade quase imediata de edição de uma nova norma, em conformidade com os novos direitos apresentados pela Convenção.

A nova definição amolda-se ao primado da justiça social e igualdade expresso no texto constitucional, uma vez que, considerando que os componentes da dignidade humana, devem ser concedidos a todos em igual medida, pois independente de limitações de ordem física ou psíquica, não é dado diferenciar os indivíduos, 
concedendo maior ou menor grau de dignidade e acesso a bens, serviços e oportunidades.

Como ressalta SASSAKI (1999, p.68) a diferença é inerente à condição humana, e diante do Estado Democrático de Direito, o esforço coletivo deve ser no sentido de desarraigar padrões de normalidade e aceitação, criando uma sociedade plural e inclusiva, capaz de gerar progresso econômico atrelado ao progresso coletivo.

Nas palavras de Farias, Cunha e Pinto (2016, p. 21):

[...]uma sociedade, portanto, é menos excludente, e, consequentemente, mais inclusiva, quando reconhece a diversidade humana e as necessidades específicas dos vários segmentos sociais, incluindo as pessoas com deficiência, para promover ajustes razoáveis e correções que sejam imprescindíveis para seu desenvolvimento pessoal e social, "assegurandolhes as mesmas oportunidades que as demais pessoas para exercer todos os direitos humanos e liberdades fundamentais". É dentro deste paradigma da inclusão social e dos direitos humanos que devemos inserir e tratar a questão da deficiência. O desafio atual é promover uma sociedade que seja para todos e onde os projetos, programas e serviços sigam o conceito de desenho universal, atendendo, da melhor forma possível, às demandas da maioria das pessoas, não excluindo as necessidades específicas de certos grupos sociais, dentre os quais está o seguimento das pessoas com deficiência.

A condição singular da pessoa com deficiência impõe que a normativa interna e internacional a vislumbre de forma a efetivar o pleno gozo de seus direitos fundamentais.

Embora avanços na positivação dos direitos humanos sejam visíveis nos instrumentos normativos de grande parte dos Estados Contemporâneos, Sarlet afirma que a dignidade da pessoa humana não tem sido efetivada no contexto prático, onde persiste desigualdades e negação de direitos. No mesmo sentido, assim se coloca Zanoti (2006, p. 126):

Apesar de o postulado da dignidade da pessoa humana ser um dos fundamentos da comunidade nacional e internacional, "[...] tendo passado a constituir o vértice para o qual se convertem todos os direitos individuais [...]"e coletivos, proclamados nas constituições democráticas, sua efetividade, principalmente na valorização do trabalho humano, ainda está por se fazer.

Nesse sentido, avulta-se a imprescindibilidade em garantir à pessoa com deficiência o direito de integrar o mercado de trabalho, cooperando com o desencolhimento econômico e social, porquanto, dessa forma estará sendo garantido o exercício da cidadania. 
Novamente, importante destacar que O Estatuto da Pessoa com Deficiência patrocina valores fundamentais para a inclusão social da pessoa com deficiência no mercado de trabalho, consignando mudanças relevantes no 'padrão de adaptação' até então considerado, sendo que, na nova dinâmica a sociedade é que deve se ajustar para permitir que qualquer indivíduo, independente de sua deficiência, possa trabalhar e desenvolver suas potencialidades enquanto pessoa humana. Nesse sentido, ensina Sassaki,(1999, p.42):

(...) Para incluir todas as pessoas, a sociedade deve ser modificada a partir do entendimento de que ela é que precisa ser capaz de atender às necessidades de seus membros. O desenvolvimento (por meio da educação, reabilitação, qualificação profissional, etc) das pessoas com deficiência deve ocorrer dentro do processo de inclusão e não como um pré-requisito para estas pessoas poderem fazer parte da sociedade, como se elas "precisassem pagar 'ingresso' para integrar a comunidade.

O processo de inclusão tem como base a máxima de que todo ser humano tem o direito de viver de forma livre, sem qualquer obstáculo ou impedimento, desenvolvendo suas potencialidades de forma plena e com a possibilidade de decidir o próprio destino.

Destarte, o Poder Público, as empresas e a sociedade, têm o dever de viabilizar a convivência social igualitária, atendendo os preceitos constitucionais e a tutela da dignidade humana.

Garantir o exercício pleno da cidadania, por meio da inclusão das pessoas com deficiência no mercado de trabalho, denota uma sociedade comprometida com o progresso social coletivo, adequada distribuição de riquezas e a redução das desigualdades sociais.

Uma sociedade inclusiva é uma sociedade repleta de riquezas, como expõem Zoninsein (2004, p. 42)

A cidadania incompleta ou a negação de direitos civis (liberdade de expressão, estado de direito, direito à justiça), de direitos políticos (direito e meios para participar do exercício do poder político) de direitos socioeconômicos (segurança econômica igualdade de oportunidades) são dimensões fundamentais de vidas socialmente empobrecidas.

O exercício da cidadania não se esgota por meio do voto, antes disso, ocorre pela efetiva participação no meio social (BONAVIDES, 2003, p.51), e opera-se, sobretudo, por meio de sua atuação ativa no mercado de trabalho, realidade que só torna-se palpável considerando a igualdade de tratamento e de oportunidades, a fim de estimular o potencial desse indivíduo, enquanto cidadão e ser humano. 
O processo democrático apenas se efetiva, por meio da participação de seus cidadãos, em pé de igualdade, tanto na esfera política, como na esfera social, propiciando progresso social. Nesse sentido, a inclusão social das pessoas com deficiência, que por muito tempo foram excluídas do status civitatis, tendo negadas o mínimo existencial, está ancorada na dignidade da pessoa humana, fundamento da república federativa do Brasil e valor inerente à condição humana, assim como, no compromisso assumido pelos Estados Democráticos de Direito.

\section{EMPRESA E ESTADO}

O desenvolvimento econômico e social de uma nação ocorre a partir das interações humanas que criam, a partir da força de trabalho e expansão de suas potencialidades, novas demandas sociais, estabelecendo direitos e deveres no ambiente empresarial a fim de tutelar a pessoa humana.

Podemos considerar que nas últimas décadas, ao lado de amplas demandas sociais, vem ganhando força o pleito por parte da sociedade, por condutas éticas e de valorização do trabalho humano diante da exploração da atividade econômica.

Em vista disso, analisar a responsabilidade social das empresas frente à valorização do trabalho humano e a inclusão social, resulta do próprio ordenamento jurídico brasileiro, a partir dos princípios sobre a ordem econômica, presentes no artigo 170 da Constituição Federal.

As relações sociais no Estado Democrático de Direito são alicerçadas na proteção da dignidade humana, fator que delimitou novos contornos ao conceito de função social da empresa, que hoje deve estar comprometida com temas relativos à inclusão social e desenvolvimento econômico pautado na sustentabilidade.

Nesse sentido, a livre iniciativa e a ordem econômica, preconizada no Artigo 170 do texto constitucional vêm acompanhadas pela valorização do trabalho humano e os ditames da justiça social, como atesta Eros Grau (2005, p.199):

No quadro da Constituição de 1988, de toda sorte, da interação entre esses dois princípios e os demais por ela contemplados - particularmente o que define como fim da ordem econômica (mundo do ser) assegurar a todos existência digna - resulta que valorizar o trabalho humano e tomar como fundamental o valor social do trabalho importa em conferir ao trabalho e seus agentes (os trabalhadores) tratamento peculiar. 
As empresas possuem uma função social que transcende os interesses individuais de seus sócios, devendo vislumbrar os interesses da sociedade na qual está inserida, a fim de consolidar desenvolvimento econômico aliado ao progresso social.

Assim, por meio da legislação interna e o compromisso assumido por meio dos tratados internacionais, o Estado Brasileiro deve atuar no sentido de oportunizar acesso e gozo aos direitos sociais das pessoas com deficiência, garantindo a cidadania por meio da inclusão no mercado de trabalho.

No entanto, a mera positivação de direitos e garantias não se mostrou, no plano concreto, suficiente para proporcionar a efetiva tutela as pessoas com deficiência, propiciando acesso e permanência no mercado de trabalho sem distinções de qualquer natureza. Dessa forma, importante considerar de forma ampla os fatores que ainda impedem a efetiva proteção do trabalhador, conforme discorre Nascimento (2000, p. 75):

\begin{abstract}
Mudar as desigualdades econômicas, culturais, de saúde, de oportunidades de trabalho da nossa população e diminuir os espaços entre o legal e o real é uma tarefa para a qual não basta o direito do trabalho. Supera os seus limites. Exige políticas públicas. Uma política econômica que promova a correção dos desníveis. Uma política educacional voltada para a ampliação das oportunidades de estudo. Uma política de saúde para quem dela necessita.Uma política previdenciária que estabeleça um verdadeiro sistema de seguridade social. Uma política de empregos capaz de realmente aumentar as possibilidades de ingresso no processo produtivo e manter o trabalho de quem o tem.
\end{abstract}

Nesse panorama, frente à conjuntura de profundas desigualdades e graves problemas sociais, imperioso estabelecer novos contornos para a atuação estatal e a responsabilidade das empresas, como forma de garantia dos objetivos fundamentais do Estado Democrático de Direito, por meio da valorização do trabalho humano sem discriminação.

Sobre o tema, cumpre destacar as possibilidades explanadas por Oliveira (2011, p. 24), como mecanismos capazes de proporcionar a valorização:

[...] como se valoriza o trabalho? Em um primeiro momento, através da geração de mais pontos de trabalho; havendo um melhor trabalho com mais satisfação, com menos riscos, com mais criatividade, com a participação de quem trabalha no gerenciamento empresarial, sem discriminação; por meio de uma melhor retribuição, com a efetivação dos direitos sociais consubstanciados nos arts. $6^{\circ}$ a 11 da CF; e uma efetiva política pública de qualificação da mão de obra, capacitando criativamente o ser humano. 
Resta imperioso, a fim de valorizar o trabalho humano, a oferta de mais zonas de trabalho, assim como melhores condições laborais, que se projetem de forma positiva no campo de proteção ao trabalhador, atendendo os princípios gerais da ordem econômica que balizam a responsabilidade social das empresas.

A relação da empresa com a comunidade ilustra os valores com os quais está comprometida, sendo que a responsabilidade social deve levar em conta que a valorização do trabalho humano passa pela necessidade de criar um ambiente de trabalho igualitário e sem discriminação, contribuindo para o pleno desenvolvimento do país.

Logo, o escopo das empresas em serem socialmente responsáveis deverá perseguir alvos múltiplos, incluindo, sobretudo, a pessoa com deficiência no mercado de trabalho.

A responsabilidade social das empresas é um grande fator de transformação na sociedade, por meio do qual se vislumbram avanços que levarão ao país ao desenvolvimento econômico, com a valorização do trabalho humano.

Em relação à cultura de exclusão das pessoas com deficiência do mercado de trabalho, o antropólogo Ribas (2009, p.212) destaca importante reflexão:

\footnotetext{
Não faz sentido contratar pessoas com deficiência apenas porque a legislação brasileira obriga e a fiscalização pune os que não a cumprem. Só faz sentido contratar pessoas com deficiência quando se parte do reconhecimento da possibilidade que essas pessoas possam ter para se desenvolver para o trabalho - e não da aceitação inquestionável do limite ou da deficiência. (...) Empresas não são organizações filantrópicas. Empresas são organizações nas quais se produz e se comercializa bens ou serviços, se geram empregos e têm a finalidade de impulsionar o mercado e provocar a circulação e o consumo da riqueza. Se não acreditarmos que as pessoas com deficiência podem gerar riqueza pelo seu próprio trabalho, é melhor não trazê-las para dentro das empresas.
}

A fim de constituir mecanismos que possibilitem a efetiva valorização do trabalho humano, faz-se necessário à implementação de medidas por parte do poder público e das empresas, para a efetiva inclusão de pessoas com deficiência no mercado de trabalho, superando estigmas arraigados no seio social para concretizar a isonomia assegurada pelo texto constitucional.

Por meio de políticas públicas, com vistas ao combate à discriminação de qualquer espécie, o Estado atende as disposições constitucionais, e ainda promove a 
abertura para que a pessoa com deficiência seja vista a partir de suas potencialidades e competências. Conforme destaca Sarlet (2007, p. 60-67):

\begin{abstract}
Consagrado expressamente no título dos princípios fundamentais, a dignidade da pessoa humana como um dos fundamentos do nosso Estado democrático (e social) de Direito (art. 1, inc. III, CF), o nosso Constituinte de 1988 - a exemplo do que ocorreu, entre outros países, na Alemanha -,além de ter tomado uma decisão fundamental a respeito do sentido, da finalidade e da justificação do exercício do poder estatal e do próprio Estado, reconheceu categoricamente que é o Estado que existe em função da pessoa humana, e não o contrário, já que o ser humano constitui a finalidade precípua, e não meio da atividade estatal.
\end{abstract}

Assim sendo, a intervenção do Estado nas relações de trabalho, se justifica diante da primordialidade em assegurar a dignidade do trabalhador diante dos 'donos do poder econômico'(FAORO, 1998), impedindo a desumanização do trabalho pelo domínio do capital.

Nesse contexto, o Decreto $\mathrm{n}^{\mathrm{o}}$ 3.298/1999 dispõe sobre a "Política Nacional para a Integração da Pessoa Portadora de Deficiência”, em sintonia com o Artigo 37, VIII da Constituição Federal, assegura às pessoas portadoras de deficiência o direito de se inscreverem em concurso público, em igualdade de condições com os demais candidatos, para o provimento de cargos cujas atribuições sejam compatíveis com suas deficiências.

A reserva de mercado no âmbito do setor público, como já mencionado, provém da disciplina do art. 37, VIII da CF/88, e com o advento da Lei n. 7.853/89, em seu artigo $2^{\circ}$, inc. III, alíneas “c” e "d", houve a reafirmação da intenção programática do legislador constituinte.

Não obstante a legislação citada, no tocante a reserva de vagas no serviço público, cumpre arguir que este mecanismo não isenta o poder público de outras medidas e ainda as empresas, que devem atuam para além de conceder emprego, garantindo que o mesmo seja exercido com dignidade e valorização do profissional com deficiência.

No mesmo sentido, o sistema de cotas para pessoas com deficiência no setor privado, encontra-se previsto no art. 93 da Lei n. ${ }^{\circ}$ 8.213/91, o qual fixa o percentual de $2 \%$ a 5\% para a contratação de pessoas com deficiência em empresas com mais de 100 empregados, com exceção das pequenas e microempresas. 
Entretanto o paradigma da inclusão, não se concretiza de forma plena, por meio reserva de vagas tanto no setor público como no âmbito privado. Cabe a integração com outros mecanismos para a inclusão das pessoas com deficiência no mercado de trabalho.

Assim, o Poder Público, por meio de incentivos fiscais, pode estimular a contratação das pessoas com deficiência e reduzir os obstáculos para a inclusão, como prevê o Artigo 278, II da Constituição Estadual de São Paulo.

Ademais, outro mecanismo apto a potencializar a inclusão, poderia ser obtido ao estabelecer como requisito à participação em licitações e obtenção de financiamentos públicos o cumprimento da legislação de cotas. Assim como, a possibilidade de isenção fiscal para os empregadores que procederem à inclusão de pessoas com deficiência na exploração da atividade econômica.

Sendo o mercado de trabalho um ambiente fértil para o desenvolvimento das potencialidades humanas e a promoção da dignidade, este deve ser protegido contra qualquer forma de discriminação, sendo que o Poder Judiciário, o Ministério Público do Trabalho e os Sindicatos exercem papel fundamental na defesa e proteção das garantias constitucionais.

O compromisso efetivo das empresas com a valorização do trabalho, enquanto elemento essencial para a efetivação dos direitos sociais das pessoas com deficiência deverá ter como promotor o Estado, que assume em sua normativa interna e internacional o compromisso de propiciar emancipação e pleno gozo dos direitos sociais as pessoas com deficiência.

Forçoso concluir o papel decisivo do Poder Público e das empresas ao ensejar a valorização do trabalho humano, por meio da inclusão das pessoas com deficiência no mercado de trabalho, dentro de um quadro de justiça social e isonomia material oportuno ao Estado Democrático de Direito, capaz de assegurar o exercício da plena da cidadania e o aperfeiçoamento democrático do país.

\section{CONCLUSÃO}

Na vigência do Estado democrático de Direito, não se admite outra intenção do que a realização plena do indivíduo e de suas potencialidades, circunstância que ganha ainda mais destaque diante do valor do trabalho humano para as sociedades modernas. 
A redução das desigualdades sociais é desafio complexo e reclama compromisso coletivo para a concreta efetivação dos direitos fundamentais dos indivíduos, podendo ser vislumbrada por meio do acesso ao mercado de trabalho, pressupostos da dignidade da pessoa humana.

Frente às ações tendentes a violar os direitos e garantias das pessoas com deficiência, alijando-as do mercado de trabalho, resulta como essencial o papel contramajoritário do Poder Judiciário, atuando no sentido de propiciar isonomia material e respeito às diferenças, sem discriminação.

Destaca-se ainda a atuação do Poder Público instituindo mecanismos que favoreçam a inclusão, seja por meio de reserva de vagas em concursos públicos ou no âmbito privado, ou ainda por meio de isenções fiscais.

A inclusão social produto inato de uma sociedade plural, em vias de aperfeiçoamento do processo democrático, deve ser feita para além da garantia de direitos mínimos, como educação, saúde e lazer; mais que isso, deve-se reverter o panorama de negação de direitos as pessoas com deficiência, rompendo com o paradigma de limitação, ampliando assim a autonomia e a participação social.

A inclusão social é pressuposto para o aperfeiçoamento do processo democrático, pois não há como estabelecer os rumos do país, delinear os pressupostos para o desenvolvimento econômico, sem a participação e contribuição de todos, respeitadas as individualidades de cada um no desenvolvimento de suas aptidões.

Todavia, não se ignora que a integração ao processo democrático é apenas um dos fatores a ser considerado na tutela aos direitos das minorias, uma vez que o compromisso para a eficaz inclusão de pessoas com deficiência também deve ser cumprido pelas empresas.

A busca de plena cidadania, em relação às pessoas com deficiência as coloca no patamar mínimo de direito a ter direitos, e nos indica o ideal fraterno de que todos os cidadãos pertencem à mesma dimensão social, sendo assim os direitos humanos, assim como todas as demais garantias resultantes da dignidade da pessoa humana, devem ser garantidos em sua totalidade, sem distinção.

O compromisso das empresas para com a sociedade, oportunizando o acesso das pessoas com deficiência ao emprego digno, favorece o exercício pleno da cidadania e contribui para a redução das desigualdades sociais, atendendo os princípios que orientam a ordem econômica e o Estado Democrático de Direito. 
Dessa forma, o Estado Brasileiro, conferindo primazia à dignidade da pessoa humana, deve garantir a eficácia, no plano concreto, dos direitos sociais das pessoas com deficiência, minimizando as desigualdades e garantindo a cidadania por meio do acesso ao mercado de trabalho, contribuindo assim para o progresso social democrático.

\section{REFERÊNCIAS}

ALVES, Fernando de Brito. Margens do direito: a nova fundamentação do direito das minorias. Porto Alegre: Núria Fabris, 2010.

ARAÚJO, Luiz Alberto David. A proteção constitucional das pessoas portadoras de deficiência. 2. ed., Brasília; CORDE, 1996.

BENINE, Renato Jaqueta. Responsabilidade social empresarial: um conceito em construção. Revista do Curso de Direito da FSG. Ano 4, n. 8, jul./dez. 2010. Disponível em: < http://ojs.fsg.br/index.php/direito/article/viewFile/728/519>. Acesso em: 03 mai. 2017.

BOBBIO, Norberto. A era dos direitos. Carlos Nelson Coutinho (Trad.). 13 $3^{\text {a }}$ tir. Rio de Janeiro: Ampus, 1992.

BONAVIDES, Paulo. Teoria constitucional da democracia participativa: por um direito constitucional de luta e resistência; por uma nova hermenêutica; por uma repolitização da legitimidade. 1. ed. São Paulo: Malheiros, 2003.

CAMBI, Eduardo. Neoconstitucionalismo e neoprocessualismo: direitos fundamentais, políticas públicas e protagonismo judiciário. São Paulo: Revista dos Tribunais, 2010.

DALLARI, Dalmo de Abreu. Direitos Humanos e Cidadania. São Paulo: Moderna, 1998.

FAORO, Raymundo. Os donos do poder: formação do patronato político brasileiro. 13. ed. São Paulo: Globo, 1998.

FARIAS, Cristiano Chaves de; CUNHA, Rogério Sanches; PINTO, Ronaldo Batista. Estatuto da Pessoa com Deficiência Comentado artigo por artigo. Salvador: Editora JusPodivm, 2016. 
GRAU, Eros Roberto. A ordem econômica na Constituição de 1988. 10.ed. São Paulo: Malheiros, 2005.

LAFER, Celso. A reconstrução dos direitos humanos: a contribuição de Hannah Arendt. Revista Estudos Avançados. v. 11, no 30, p. 55-65. São Paulo: Instituto de Estudos Avançados da Universidade de São Paulo, maio-ago, 1997. Disponível em: <http://www.scielo.br/pdf/ea/v11n30/v11n30a05.pdf>. Acesso em: 07 mai. 2017.

MELO, Adriana Zawada. Direitos Sociais, igualdade e dignidade da pessoa humana. Revista Mestrado em Direito. Osasco:SP, Ano 7, n 1. Jan-Jun. 2007.

MIRANDA, Jadiael Galvão. Direito da Seguridade Social: direito previdenciário, infortunística,Assistência Social e Saúde. Rio de Janeiro: Elsevier, 2007.

NASCIMENTO, Amauri Mascaro. Iniciação ao Direito do Trabalho. 26.ed. São Paulo: LTr, 2000.

OLIVEIRA, Lourival José de. Direito do Trabalho segundo o Princípio da Valorização do Trabalho Humano: Estudos dirigidos para alunos de graduação. São Paulo: LTr, 2011.

PIOVESAN, Flávia. Direitos Humanos e o Direito Constitucional Internacional. 10. ed. São Paulo: Saraiva, 2009.

Convenção da ONU sobre os Direitos das Pessoas com Deficiência: inovações, alcance e impacto. In: FERRAZ, Carolina, Valença. et al. (Coord). Manual dos Direitos das Pessoas com Deficiência. São Paulo: Saraiva, 2012.

RIBAS, João Baptista Cintra. Por que empregar pessoas com deficiência? In: FREITAS, Maria Nivalda de Carvalho; MARQUES, Antônio Luiz (Org.). Trabalho e pessoas com deficiência - pesquisas, práticas e instrumentos de diagnóstico. Curitiba: Juruá, 2009.

ROCHA, Cármen Lúcia Antunes. O princípio da dignidade da pessoa humana e a exclusão social. Revista de Interesse Público, Porto Alegre, no. 04, p. 23/47, 1999.

SARLET, Ingo Wolfgang. Dignidade da Pessoa Humana e Direitos Fundamentais na Constituição Federal de 1988. 5.ed. Porto Alegre: Livraria do Advogado, 2007. 
A eficácia dos direitos fundamentais. 2. ed., rev. e atual. Porto Alegre: Livraria do Advogado, 2001.

SASSAKI, Romeu Kasumi. Inclusão: Construindo Um a Sociedade Para Todos. $3^{\text {a }}$ edição. Rio de Janeiro: WVA, 1999.

SILVA, José Afonso da. Curso de direito constitucional positivo. 17. ed. rev. atual. São Paulo: Malheiros, 2000.

SILVA, Paulo Henrique Tavares. Valorização do Trabalho como Princípio Constitucional da Ordem Econômica Brasileira: Interpretações Críticas e Possibilidades de Efetivação. Juruá, 2003.

VIEIRA, Maria Margareth Garcia. A globalização e as Relações de Trabalho, Curitiba: Juruá, 2000.

ZANOTI, Luiz Antonio Ramalho. A Função Social da Empresa Como Forma de Valorização da Dignidade da Pessoa Humana, Marília, Unimar, 2006.

ZONINSEIN, Jonas. O caso econômico para combater a exclusão racial e étnica. In: BUVINIC, Mayra; MAZZA, Jacqueline; DEUTSCH, Ruthanne. Inclusão social e desenvolvimento econômico na América Latina. Tradução: Hilda Maria L. P. Coelho. Rio de Janeiro: Elsevier; Washington: BID, 2004. 